\title{
ESPAÇOS NA CRECHE: ORGANIZAÇÃO E REFLEXÕES COLABORATIVAS
}

\author{
Ana Rosa Costa Picanço Moreira ${ }^{1}$ \\ Aretusa Santos Rosa ${ }^{2}$ \\ Clarice de Medeiros Devêza ${ }^{3}$
}

\section{INTRODUÇÃO}

A organização dos espaços da creche vem ganhando fôlego nas pesquisas e documentos nas últimas décadas, chamando a atenção para a sua dimensão educativa. Apesar do avanço considerável, ainda pouco se discute sobre o tema na formação inicial de professores. Assim, muitos ambientes da creche têm sido organizados menosprezando suas especificidades - um contexto de educação/cuidado da criança de zero a três anos. Por vezes, a lógica hospitalar tem orientado o planejamento espacial dos berçários, sobrecarregando esses ambientes com berços padronizados e paredes vazias, enquanto a lógica escolar tem se mostrado presente nas salas de referência destinadas a crianças de dois e três anos de idade. Nos berçários, há poucas mobílias e estruturadores espaciais, sendo esses muitas vezes pobres ou sem sentido para os bebês, como móbiles e painéis estereotipados fixados distantes dos bebês. Do mesmo modo, para a composição dos ambientes destinados às crianças pequenas, têm prevalecido mesas e cadeiras de pequenas dimensões e murais, que tomam como referência as salas de aula do ensino fundamental. Tais organizações espaciais revelam o quanto as práticas de cuidado/educação da creche ainda estão presas às amarras históricas da guarda, assistencialismo e escolarização, e à postura adultocêntrica dos professores, dificultando a apropriação desses ambientes pelas crianças, na medida em que desconsideram os seus interesses e necessidades.

Em conformidade com as Diretrizes Curriculares Nacionais para a Educação Infantil - DCNEI (BRASIL, 2010), que caracterizam a organização espacial como um componente da proposta pedagógica, entendemos que o espaço orienta

\footnotetext{
${ }_{1}^{1}$ Universidade Federal de Juiz de Fora. ana.moreira@ufjf.edu.br

2 Universidade do Estado do Rio de Janeiro. saaretusa@gmail.com

${ }^{3}$ Universidade Federal de Juiz de Fora. claricemdeveza@gmail.com
} 
as ações educativas e é por elas orientado, não sendo, portanto, simplesmente o local onde as práticas pedagógicas acontecem (MOREIRA, 2011). Como afirma Faria (1999, p. 70), "a pedagogia se faz no espaço e o espaço se faz na pedagogia".

Nessa direção, parece-nos importante que a ideia de espaço seja problematizada com os professores, no sentido de interrogá-los sobre o lugar que a organização espacial tem ocupado na sua prática pedagógica convidando-os a construírem outros olhares, olhares estrangeiros, sobre a organização espacial. A formação em serviço, sobretudo por meio do processo colaborativo entre universidade e creche, pode ser um caminho interessante para a problematização e ressignificação de questões cotidianas com os educadores, muitas vezes naturalizadas e cristalizadas. De acordo com Ibiapina (2016), essa perspectiva de trabalho colaborativo é orientada pelo princípio da reflexão crítica, para a qual "[...] a reflexão é considerada como processo de base material responsável pela recordação e pelo exame de realidade com o objetivo de transformá-la" (IBIAPINA, 2016, p. 45). No entanto, reflexão, apesar de se tratar de um processo mental e intrapsicológico, somente ocorre em contextos de colaboração.

Outro aspecto importante de nosso trabalho é que a teoria não deve se sobrepor às experiências dos educadores, nem tampouco as experiências devem fugir da análise crítica. Nesse sentido, a problematização das práticas pedagógicas em diálogo com a teoria pode se constituir num potente desencadeante de mudanças e fortalecimento das ações dos educadores. Como destaca Bodnar (2013, p. 210), "O ponto de partida para esse diálogo deve ser a própria prática pedagógica, que contém em si uma teoria - que, para se tornar práxis, precisa ser refletida, e, a partir daí, transformada."

Diante do que foi exposto, este trabalho tem o objetivo de discutir uma experiência de formação em serviço onde o espaço físico foi o fio condutor das reflexões sobre as práticas pedagógicas na creche. Trata-se de uma experiência colaborativa entre a universidade e a creche a partir do diálogo entre um projeto de extensão, elaborado pelo grupo de pesquisa Ambientes e Infâncias (GRUPAI/UFJF), e um projeto de trabalho, elaborado pelos profissionais da creche. 


\section{ORGANIZAÇÃO ESPACIAL E/NA PRÁTICA PEDAGÓGICA}

É crescente o número de estudos sobre a organização de ambientes da creche que têm contribuído para se pensar sobre o papel do espaço nas ações pedagógicas. Campos-de-Carvalho (1993), Campos-de-Carvalho e Mingorance (1999), Campos de Carvalho e Souza (2008), Bomfim e Campos-de-Carvalho (2006), Meneghini e Campos-de-Carvalho (2003) e Moreira (1992) realizaram pesquisas sobre organização dos espaços nas salas de referência, por meio da criação de zonas circunscritas, que são áreas delimitadas por, no mínimo, três barreiras, formadas por objetos, mobílias ou elementos arquitetônicos, que fecham essas áreas. De um modo geral, os resultados demonstraram que a presença dessas zonas propicia o aumento da intensidade de brincadeiras e interações, que são os eixos do trabalho pedagógico, conforme definem as DCNEI (BRASIL, 2010). Além disso, tais estudos demonstraram que o tipo de arranjo espacial (LEGENDRE, 1983) afeta a distribuição de crianças pelo ambiente, podendo favorecer ou não a ocorrência de deslocamentos e movimentos mais autônomos.

Embora essas pesquisas apontem para a relação entre espaço e pessoa, entendemos que ela não acontece de forma direta, mas sim mediada por significações histórica e socialmente construídas. Nosso entendimento está ancorado na teoria histórico-cultural de Vigotski a qual nos oferece uma leitura dialógica da relação homem-mundo, afirmando que espaço e pessoa não se opõem, mas, ao contrário, são compreendidos como aspectos interdependentes, formando uma unidade, visto que um não existe sem o outro (VIGOTSKI, 1935/2010).

Para esse autor, o espaço se constitui num contexto de interações que vai ganhando novos sentidos conforme as vivências cotidianas dos sujeitos. Dessa forma,

[...] no começo também se trata de um mundo muito pequeno, o mundo do quarto, o mundo do parque mais próximo, da rua. Com os passeios, seu mundo aumenta e, cada vez mais, novas relações entre a criança e as pessoas que a circundam tornam-se possíveis. [...] Cada idade possui seu próprio meio, organizado para a criança de tal maneira que o meio, no sentido puramente exterior dessa palavra, se modifica para a criança a cada mudança de idade (VIGOTSKI, 1935/2010, p.683). (grifo nosso)

A relação presente entre pessoa e meio é sintetizada por Vigotski no conceito de vivência, unidade indivisível que reúne o que é retirado do meio pelo sujeito como aquilo que é retirado da personalidade do sujeito. A vivência opera com 
particularidades do meio e da pessoa (VIGOTSKI, 1935/2010). Sendo a vivência a condição própria e singular de cada contexto de ser e estar do sujeito no mundo, é ela que possibilita a emergência de significações [sempre particulares] para os significados [sociais] do meio. O espaço, portanto, é sempre um campo de possibilidades onde cada sujeito produz o seu, na medida em que as pessoas constroem sentidos particulares sobre o espaço a partir dos significados que a cultura Ihes apresenta.

Segundo Lopes (2012, p. 155), existe “(...) um contexto ofertado em cada tempo histórico para nossos bebês pelas gerações que as precedem e que com ela se encontram." Isto significa dizer que as organizações espaciais são histórica e culturalmente condicionadas. Porém, elas encontram-se prenhas de serem permanentemente ressignificadas pelas vivências dos sujeitos.

\section{COLABORAÇÕES ENTRE A CRECHE E A UNIVERSIDADE}

A experiência aqui relatada retrata uma possibilidade de aproximação e interlocução entre os saberes da creche e os saberes da universidade. Configura-se no projeto "Ambientes da infância e formação dos profissionais da creche" (PROEX/UFJF), que está sendo desenvolvido em uma creche pública do município de Juiz de Fora, Minas Gerais, desde 2015. Apostamos que estudos de natureza interventiva possam se constituir em um contexto fértil de formação continuada em serviço e de formação inicial docente.

O projeto tem o objetivo de criar situações de reflexão colaborativa e crítica entre educadores (coordenadora, educadoras que atuam nas salas e demais funcionários) e membros da universidade (professora e bolsistas do curso de Pedagogia) a respeito das práticas cotidianas, tendo como fio condutor o espaço. Sobre essa abordagem metodológica, Ibiapina (2015, p. 47) adverte que:

[...] a colaboração pressupõe que todos os agentes tenham voz e vez para colocar suas experiências, compreensões e suas concordâncias e discordâncias em relação aos discursos dos outros parceiros. Nos trabalhos colaborativos, os partícipes se colocam como aprendizes, apreendendo com as experiências, os conhecimentos, as reflexões, objetivos e organização cognitiva e afetiva do outro. 
No movimento dialógico de escuta e questionamentos, buscamos refletir em conjunto sobre as organizações dos diferentes ambientes da creche e as vivências dos bebês e das crianças com esses espaços.

Escolhemos essa creche pelo motivo de a coordenadora ter se mostrado sensível à questão espacial, percebida por nós em visitas institucionais anteriores e discussões em outros contextos de formação em serviço promovidos pela universidade e Secretaria de Educação, além de as educadoras terem desenvolvido o projeto de trabalho "Reflexões sobre os espaços" ao longo dos meses entre março e novembro de 2013 , e estarem motivadas a retomarem e ampliarem as reflexões que emergiram naquele momento.

A creche atende aproximadamente a 150 crianças com idades entre três meses e três anos e onze meses, oriundas do bairro onde está localizada e adjacências. A instituição situa-se numa região da cidade que mescla paisagem rural com urbana. É considerada uma das maiores creches da rede municipal em extensão, possuindo área verde em todo o entorno da edificação, solários, pátios interno e externo, salas de referências (berçários e salas de atividade), brinquedoteca, sala multiuso, sala de artes, sala de leitura (Literakids), refeitório, sala das educadoras, secretaria, banheiros, despensa e cozinha. As salas de referência são em número de dez, e abarcam agrupamentos de bebês e crianças por faixa etária (BI, BII a, BII b, BII c, 2 anos a, 2 anos b, 2 anos c, 3 anos a, 3 anos b e 3 anos $c$ ). Trabalham na creche 27 educadores, dos quais 16 são do sexo feminino e atuam diretamente com as crianças nas salas; uma coordenadora; uma secretária; duas cozinheiras; e sete auxiliares de serviços gerais (dois homens e cinco mulheres).

De acordo com o Projeto Político Pedagógico da creche (PPP) de 2014, a preocupação com a organização dos espaços é constante, como pode ser visto no fragmento a seguir retirado desse documento: “(...) também discutimos e refletimos sobre a organização dos diversos espaços da creche e organizamos de dois em dois meses algum espaço para ser modificado" (PPP, 2014, p. 14). A proposição de reorganizar os ambientes permanentemente foi fruto do projeto de trabalho citado, 0 qual possibilitou aos educadores repensar e redimensionar o papel dos espaços em suas práticas, buscando qualificá-los a partir da participação das crianças e famílias. 
Tanto o PPP de 2014 quanto o projeto "Reflexões sobre os espaços" nos forneceram subsídios para a elaboração do projeto de extensão, que precisava fazer sentido para as educadoras, crianças e famílias.

\section{A PRODUÇÃO DOS DADOS}

Iniciamos as observações participantes, a produção de fotos e notas de campo sobre a vivência dos espaços pelas educadoras, bebês e crianças, em períodos de quatro horas, distribuídas pelos cinco dias da semana, o que nos permitiu conhecer melhor a dinâmica espacial nos diferentes agrupamentos. Esses instrumentos e técnicas, em interação com os documentos elaborados pela creche, nos possibilitaram identificar características espaciais dos diferentes ambientes, que apesar de sua historicidade e contexto sócio-cultural específico, não fugia do que comumente é encontrado nas creches brasileiras.

É importante ressaltar que a organização das salas de referência de bebês e crianças está condicionada aos projetos de trabalho desenvolvidos na creche, com destaque para os efeitos do projeto "Reflexão dos espaços".

Encontramos na sala do Berçário I uma grande área ocupada por berços, dispostos um do lado do outro, formando duas fileiras, além de outra de cadeiras de alimentação encostadas na janela. Entre as fileiras de berços, e situado no centro da sala, forma-se um corredor, que é a área onde geralmente os bebês permanecem no chão, engatinhando, andando ou brincando com brinquedos de pequenas dimensões e caixas temáticas, construídas pelas próprias educadoras. Também fazem parte desse cenário alguns móbiles pendurados no teto os quais podem ser explorados visualmente pelos bebês, porém eles só podem ser tocados quando os bebês estão no colo dos adultos.

Nas salas do Berçário II não existem berços. Tatames, móbiles, cantos temáticos e murais são os principais estruturados espaciais. Os cantos são formados na área periférica das salas pelas educadoras a partir de temas que fazem parte do cotidiano das crianças, tais como carrinho, boneca, casinha, salão de beleza. Eles são montados em determinados momentos do dia em que a brincadeira é a atividade privilegiada.

Nas salas de dois e três anos estão presentes mesas, cadeiras, murais diversos (alguns construídos pelas educadoras e outros com as produções das 
crianças), além de cantos temáticos, que têm mais tempo de permanência em comparação com os cantos temáticos dos berçários, pois aqueles estão estritamente vinculados aos projetos de trabalho. Caixas de brinquedos, livros e revistas também fazem parte desses ambientes, mas não são acessíveis às crianças a qualquer hora. De um modo geral, os arranjos espaciais lembram ambientes escolares, que auxiliam as educadoras a proporem atividades dirigidas.

Os espaços externos contêm alguns equipamentos lúdicos (trepa-trepa, manilhas, pneus) e troncos de árvore deitados no chão, que convidam às crianças a subirem, descerem, escorregarem, rodopiarem etc. Sendo amplos e com o chão de areia e/ou grama, eles favorecem brincadeiras que envolvem corrida.

\section{ENCONTROS REFLEXIVOS}

Em junho de 2015, iniciamos os encontros reflexivos, que são os contextos de reflexão colaborativa de formação docente, criados a partir do projeto. Os encontros são previamente agendados com a coordenadora da creche. Até agora, foram realizados seis encontros reflexivos, com duração de duas horas cada. Para efeitos deste trabalho, apresentaremos as análises dos três primeiros, que aconteceram na própria creche.

Os dois primeiros encontros ocorreram somente com parte do grupo das educadoras de sala, ou seja, as educadoras que atuavam nas salas de dois e três anos (encontro 1) e educadoras das salas de berçário (encontro 2). O terceiro encontro contou com a participação de todos os educadores porque foi Dia Pedagógico, e não havia crianças na creche. Cada encontro foi gravado e, posteriormente, feita a transcrição e análise dos dados.

No início do primeiro encontro de cada grupo de educadoras, cada uma se apresentou a partir de suas preferências espaciais na creche. Interessante notar que as educadoras dos agrupamentos de dois e três anos elegeram ambientes diversos da creche, tais como o pátio, a sala das educadoras, o solário, a sala multiuso e a sala de leitura, justificando as suas escolhas com base nas memórias de infância e traços de personalidade. Já as educadoras dos berçários escolheram as salas em que trabalham devido à sensação de acolhimento que esses ambientes Ihes proporcionam. Uma possível análise desses relatos sugere certa identificação das educadoras com as crianças com as quais trabalham a partir de suas 
concepções e práticas desenvolvidas com bebês e crianças de dois e três anos nesses ambientes. De um modo geral, os bebês passam grande parte do dia em suas salas de referência, enquanto que as crianças de dois e três anos circulam mais pelos outros espaços da creche.

Em seguida, propusemos que as educadoras refletissem sobre um fragmento da poesia de Manuel de Barros "O apanhador de desperdícios", que trata do respeito e da valorização de "coisas desimportantes" no mundo contemporâneo. Solicitamos que elas procurassem traçar relações dos versos com a temática do espaço. Várias educadoras destacaram as sucatas como "coisas desimportantes" para muitas pessoas no mundo atual, que é marcado pela cultura do consumo. As sucatas foram ressignificadas por elas como matéria-prima para a confecção de brinquedos, mobílias, e outros estruturadores espaciais. Algumas recordaram do projeto de trabalho sobre o espaço da creche e disseram que pretendiam construir uma casa utilizando caixas de leite. Outras mencionaram que a creche dispõe de poucos brinquedos industrializados para o número de crianças que atendem. Disseram que aproveitam embalagens vazias, caixas, retalhos de pano para confeccionarem brinquedos para as crianças. Indagamos a possibilidade de as crianças construírem com elas os brinquedos, tendo participação autoral. Destacaram também a participação das famílias no envio de sucatas para a creche e na confecção de brinquedos. Questionamos sobre a possibilidade de as famílias participarem de modo mais colaborativo, ou seja, construindo os brinquedos junto com as educadoras em contextos de oficina, por exemplo.

Outro ponto interessante sobre a poesia foi a analogia que algumas educadoras fizeram do quintal com a creche, que aparece no verso "meu quintal é maior do que o mundo". Para essas educadoras a creche não termina nas paredes ou "muros da creche"; ela abarca o entorno da instituição, como as montanhas, as ruas e a fazendinha, que fica localizada no fim da rua. Das janelas e do pátio externo, elas relatam trazer esses espaços para dentro da creche e os inserem em seu fazer pedagógico, tensionando a falsa dicotomia da relação interno-externo (COELHO-NETTO, 2002).

O "quintal" também foi comparado com a imaginação das crianças quando elas estão brincando de faz de conta. "O quintal é como o mundo de imaginação das crianças", disse uma educadora e as demais concordaram. Elas 
afirmam que por meio da imaginação, a sala e os outros ambientes da creche se transformam em outros cenários que aguçam ainda mais a imaginação das crianças.

Problematizamos assim os ambientes que oferecemos às crianças como "prontos" ou "ideais" e a ressignificação que elas fazem sobre eles. Recuperamos o que diz Vigotski (1935/2010) sobre as significações que as crianças constroem sobre o meio (espaço/ambiente). Ou seja, o ambiente está sempre prenhe de ser ressignificado pelas pessoas que o vivenciam. Nas brincadeiras e interações com e nos ambientes, as crianças criam novas significações para eles, produzindo sentidos outros que atendam às suas necessidades.

Ainda nesses dois encontros, lançamos as seguintes perguntas "Que espaço eu tenho na creche?" e "Que espaço eu desejo?" A primeira pergunta procurou saber como elas percebiam os seus ambientes de trabalho. Mais uma vez, os ambientes caracterizados ultrapassaram as salas de referência. Aspectos positivos, tais como a dimensão, a ventilação e a iluminação das salas; os cantos temáticos construídos por elas (cantinho da leitura e cantinho da beleza); as mesas e cadeiras que são transformadas pelas crianças em carros, cabanas e casas, foram destacadas pelas educadoras das salas de dois e três anos. Já as educadoras dos berçários enfatizaram a funcionalidade da arquitetura dos ambientes, especialmente a bancada para o banho que existe na sala do Berçário l e os banheiros que existem dentro das salas de Berçário II, facilitando a realização da higiene dos bebês, e a organização espacial que Ihes permite visualizarem todos os bebês. Esse grupo também destacou a presença da barra de apoio e do espelho na sala do Berçário I, objetos que consideram favorecer o desenvolvimento da motricidade e da identidade dos pequenos. Discutimos o quão o ambiente pode favorecer ou não as ações das crianças e as práticas pedagógicas, e não ser apenas pano de fundo. Os aspectos físicos dos ambientes foram interpretados por elas como aliados das práticas cotidianas quando contribuíam para a realização de suas propostas.

Sobre a segunda pergunta, que versou sobre o espaço desejado, a maioria delas apontou a necessidade de a creche adquirir brinquedos novos e em maior quantidade, pois disseram que os que existem são em número reduzido e alguns deles se encontram em condições precárias de uso. Algumas educadoras dos Bll desejaram que houvesse espelho em suas salas para qualificar as brincadeiras de faz de conta. Para uma delas, o espelho amplia o universo dos bebês, assim como o quintal poetizado por Manoel de Barros, que é maior do que o 
mundo real. Problematizamos que os aspectos físicos do ambiente são necessários, mas não são suficientes para definirmos um ambiente como favorável à aprendizagem e ao desenvolvimento infantil. Questionamos a qualidade das relações estabelecidas entre as crianças e os brinquedos no que se refere ao acesso, à escolha, aos tempos e espaços do brincar, bem como a postura das educadoras nas brincadeiras, que, muitas vezes, fica restrita a observação e intervenção em momentos de conflito, como disputa de brinquedos.

Conforme enfatiza Ibiapina (2016), compartilhar significados e negociar sentidos é imprescindível para que as aproximações e os distanciamentos entre pensamentos e ações possam ser questionadas e novas/outras compreensões possam emergir.

O terceiro encontro reflexivo congregou todos os funcionários da creche. Iniciamos com algumas memórias dos encontros anteriores trazidas por algumas educadoras, e refletimos coletivamente sobre a relação dos espaços da creche com a prática pedagógica e como poderíamos qualificar esses espaços. As discussões giraram em torno da relação estreita que a creche estabelece com as famílias das crianças, e elas relembraram alguns projetos de trabalho nos quais as famílias participaram efetivamente, seja na construção de brinquedos com as educadoras e crianças, seja na contação de histórias.

De um modo geral, os educadores demonstraram o desejo de retomar essa experiência de construção de objetos e brinquedos com as famílias com o intuito de enriquecer fisicamente as salas de referência e os outros ambientes da creche. Assim, propusemos que eles se agrupassem por segmentos (educadoras dos berçários, educadoras das salas de dois anos, educadoras das salas de três anos e educadores que não atuam diretamente nas salas) e planejassem algumas construções para serem feitas com as famílias, em oficinas, considerando os interesses e demandas das crianças e dos bebês.

O resultado foi a ideia de elaborar subprojetos que envolvessem mais as famílias no trabalho pedagógico da creche, como a construção de uma casinha e mobílias para o solário; a confecção de carrinhos; e a construção de um personagem para interagir com crianças e adultos, proposta pelos auxiliares de serviços gerais.

Tais subprojetos estão sendo desenvolvidos com as famílias ao longo deste ano, estreitando as relações de parceria entre elas. 


\section{CONSIDERAÇÕES FINAIS}

Este texto teve por objetivo relatar uma experiência com projeto de formação em serviço de educadores de creche, tendo como fio condutor das discussões a organização espacial. $O$ projeto tem procurado envolver todos os sujeitos que dele participam no processo de reflexão crítica e problematização dos espaços, bem como na construção coletiva de respostas para responder aos desafios cotidianos.

Tal experiência tem sinalizado que ações de intercâmbio e colaboração entre universidade e creche, mediante a problematização e discussão de questões cotidianas, podem contribuir significativamente para um olhar mais cuidadoso sobre a organização espacial na creche, bem como a valorização dessa temática nos contextos de formação docente inicial e/ou continuada.

\section{REFERÊNCIAS}

BODNAR, Rejane Teresa Marcus Relação teoria-prática na formação em serviço de profissionais de educação infantil: ressignificando a prática pedagógica. In: ROCHA, Eloisa A. C.; KRAMER, Sônia. Educação infantil: enfoques em diálogo. $3^{\text {a }}$ ed. Campina, SP: Papirus, 2013.

BOMFIM, Joseane; CAMPOS-DE-CARVALHO, Mara Inez. Intercambios sociales en niños de 1-2 años y arreglos espaciales en guarderías brasileñas. Medio Ambiente y Comportamiento Humano, Espanha, n.7, v. 1, p. 67-88, 2006.

BRASIL. Ministério da Educação e do Desporto. Referencial curricular nacional de educação infantil. Brasília: MEC/SEF, 1998b. 3v.

. Práticas cotidianas na Educação Infantil. Bases para reflexão sobre as orientações curriculares. Brasília: MEC/SEB, UFRG, 2009.

. Ministério da Educação. Secretaria de Educação Básica. Diretrizes

Curriculares Nacionais para a Educação Infantil. Brasília: MEC/SEB, 2010.

CAMPOS-DE-CARVALHO, Mara Inez. Psicologia Ambiental: Algumas

considerações. Psicologia: Teoria e Pesquisa, n. 2, p. 435-447, 1993.

. Arranjo espacial. In: CAVALCANTI, Silvia; ELALI, Gleice (Orgs.) Temas

Básicos em psicologia Ambiental. São Paulo: Vozes, 2011.

CAMPOS-DE-CARVALHO, Mara Inez; MINGORANCE, Regina. Zonas circunscritas e ocupação do espaço por crianças pequenas em creche. Interamerican Journal of Psychology. Porto Rico, n. 33, v. 2, p. 67-89, 1999. 
CAMPOS-DE-CARVALHO, Mara Inez; RUBIANO, Márcia. Organização do espaço em instituições pré-escolares. In: OLIVEIRA, Zilma Moraes Ramos. Educação infantil: muitos olhares. São Paulo: Cortez. 1994.

CAMPOS-DE-CARVALHO, Mara Inez; SOUZA, Tatiana N. Psicologia Ambiental, Psicologia do desenvolvimento e Educação Infantil: Integração possível?. Paidéia, n.18, p. 25-40, 2008.

COELHO-NETTO, J. Teixeira. A construção do sentido na arquitetura. São Paulo: Perspectiva, 2002.

CRECHE COMUNITÁRIA LINHARES. Reflexões sobre os espaços, 2013. Projeto Político Pedagógico, 2014.

FARIA, Ana Lúcia G. O espaço físico como um dos elementos fundamentais para uma pedagogia da Educação Infantil. In: FARIA, Ana Lúcia G.; PALHARES, Marina. (Orgs.) Educação Infantil pós-LDB: rumos e desafios. Campinas, SP: Autores Associados, 1999.

IBIAPINA, Ivana Maria Lopes de Melo. Reflexões sobre a produção do campo teórico-metodológico das pesquisas colaborativas: gênese e expansão. In: IBIAPINA, Ivana Maria Lopes de Melo; BANDEIRA, Hilda Maria Martins; ARAUJO, Francisco Machado (Orgs.). Pesquisa colaborativa: multirreferenciais e práticas convergentes. Teresina: EDUFPI, 2016.

LEGENDRE. Alain Approprriation par les enfants de l"environnement architectural. Enfance, Paris, n. 3, p.389-395, 1983.

LOPES, Jader Janer Moreira. Os bebês, as crianças pequenas e suas condições histórico-geográficas: algumas notas para debate teórico-metodológico. Revista Educação em foco. Diálogo entre as teorias da atividade e sócio-histórico-cultural. ISCAR Brasil e II Fórum Nacional. Edição especial. Juiz de Fora, MG, p. 151-161, ago. 2012.

MENEGHINI, Renata; CAMPOS-DE-CARVALHO, Mara Inez. Arranjo espacial na creche: espaços para interagir, brincar isoladamente, dirigir-se socialmente e observar o outro. Psicologia: Reflexão e Crítica. v. 16, n.2, p. 367-378, 2003.

MOREIRA, Ana Rosa Costa Picanço. Transformações espaciais e interação social entre crianças de dois anos de idade - uma proposta educacional para a creche. Dissertação de Mestrado. Universidade Gama Filho. Rio de Janeiro, 1992.

Ambientes da infância e formação do educador: arranjo espacial no berçário. Tese de Doutorado. Universidade do Estado do Rio de Janeiro, Rio de Janeiro, 2011.

VIGOTSKI, Lev Semionovich. Quarta aula: a questão do meio na pedologia.

Psicologia USP, São Paulo, v.21, n.4, p. 681-701, 2010. (Texto original) 